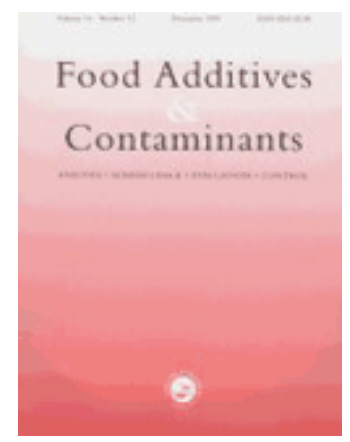

\title{
Dietary exposure to flavouring substances: from screening methods to detailed assessments using food consumption data collected with EPIC-Soft software
}

\begin{tabular}{|c|c|}
\hline Journal: & Food Additives and Contaminants \\
\hline Manuscript ID: & TFAC-2009-223.R1 \\
\hline Manuscript Type: & Original Research Paper \\
\hline $\begin{array}{r}\text { Date Submitted by the } \\
\text { Author: }\end{array}$ & 12-Oct-2009 \\
\hline Complete List of Authors: & $\begin{array}{l}\text { Crispim, Sandra; Wageningen University, Division of Human } \\
\text { Nutrition; National Research Institute for Food and Nutrition } \\
\text { Geelen, Anouk; Wageningen University, Division of Human Nutrition } \\
\text { Le Donne, Cinzia; National Research Institute for Food and Nutrition } \\
\text { de Vries, Jeanne; Wageningen University, Division of Human } \\
\text { Nutrition } \\
\text { Sette, Stefania; National Research Institute for Food and Nutrition } \\
\text { Raffo, Antonio; National Research Institute for Food and Nutrition } \\
\text { Siebelink, Els; Wageningen University, Division of Human Nutrition } \\
\text { Ocke, Marga; National Institute for Public Health and the } \\
\text { Environment } \\
\text { van't Veer, Pieter; Wageningen University, Division of Human } \\
\text { Nutrition } \\
\text { Leclercq, Catherine; National Research Institute for Food and } \\
\text { Nutrition } \\
\text { on behalf of EFCOVAL consortium, - }\end{array}$ \\
\hline Methods/Techniques: & Exposure assessment \\
\hline Additives/Contaminants: & Flavourings \\
\hline Food Types: & Ingredients \\
\hline
\end{tabular}




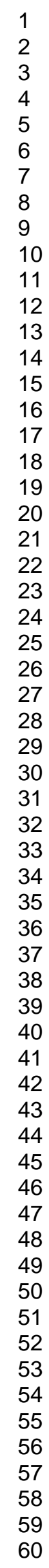

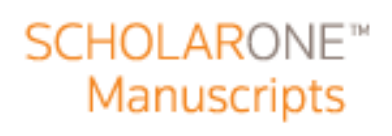

7

25

26

27

29

30

32

33

34

35

36

37

39

40

41

42

44

45

46

47

48

49

51

52

54

55 
1 DIETARY EXPOSURE TO FLAVOURING SUBSTANCES: FROM SCREENING METHODS

2 TO DETAILED ASSESSMENTS USING FOOD CONSUMPTION DATA COLLECTED WITH

3 EPIC-SOFT SOFTWARE

4

5 Sandra P. Crispim ${ }^{1}$, Anouk Geelen ${ }^{1}$, Cinzia Le Donne ${ }^{2}$, Jeanne H. M. de Vries ${ }^{1}$, Stefania

6 Sette $^{2}$, Antonio Raffo $^{2}$, Els Siebelink ${ }^{1}$, Marga Ocke ${ }^{3}$, Pieter van't Veer $^{1}$, Catherine Leclercq ${ }^{2}$

7 on behalf of the EFCOVAL consortium

8

$9 \quad{ }^{1}$ Division of Human Nutrition, Wageningen University (WU),

10 Bomenweg 2, Wageningen 6703 HD, The Netherlands.

$11{ }^{2}$ National Research Institute for Food and Nutrition (INRAN)

12 Via Ardeatina, 546, 00178, Rome, Italy

$13{ }^{3}$ National Institute for Public Health and the Environment (RIVM)

14 PO Box 1, Bilthoven, 3720 BA, The Netherlands.

15

16 Corresponding author:

17 Dr. Catherine Leclercq

18 National Research Institute for Food and Nutrition (INRAN) 
19

\section{ABSTRACT}

AIM: To compare different methods of assessing dietary exposure to flavourings in the context of a stepwise approach.

METHODS: The dietary exposure to four flavourings was determined: raspberry ketone, glycyrrhizinic acid, coumarin, and caffeine. When dietary exposure exceeded the safety limits, the need for more detailed assessment using less aggregated data was judged necessary. First, screening methods (Maximized Survey-Derived Daily Intake - MSDI, Single-Portion Exposure Technique - SPET and modified Theoretical Added Maximum Daily Intake mTAMDI) were applied. Next, individual food consumption data were used for creating models with different levels of detail to identify the foods: a model based on food groups and models based on food items. These were collected from 121 Dutch adults using a standardized 2x24h-dietary recall (EPIC-Soft) in the European Food Consumption Validation (EFCOVAL) study. Three food item models were developed: without improvements of the flavouring descriptor built in the software; with improvements; with use of non-specified flavour descriptors.

RESULTS: Based on results of at least one of the three screening methods, refined assessment was necessary for raspberry ketone, glycyrrhizinic acid and caffeine. When applying the food group model, the need for refinement was indicated for the four flavourings. When applying the food item models, only glycyrrhizinic acid and caffeine presented dietary exposure above the safety limits. In the raspberry ketone case, dietary exposure increased when improvements in food description were considered. The use of non-specified flavour descriptors hardly changed the results.

CONCLUSION: The collection of detailed food consumption data at the individual level is useful in the dietary exposure assessment of these flavourings. 
47

48

49

50

51

52

53

54

55

56

57

58

59

60

61

62

63

64

65

66

67

68

69

70

71

72

73

74

75

\section{INTRODUCTION}

More than 2700 flavouring substances (hereafter called 'flavourings') are currently registered and can be added to foods and beverages in the European Union (European Commission 1999, European Commission 2002, European Commission 2004, European Commission 2005). Accordingly, the Joint FAO/WHO Expert Committee on Food Additives (JECFA) and the European Food Safety Authority (EFSA) have been working towards the safety evaluation of flavourings in order to provide a positive list of these substances (EFSA 2009, WHO 2009). Within the safety evaluation procedure of any chemical substance, one crucial step is the dietary exposure assessment.

A major pitfall of dietary exposure assessment to chemicals is the limited availability of the two types of information that are needed, food consumption data and chemical concentration in foods (EFSA 2005). The ideal situation of performing a detailed dietary exposure assessment by collecting information at the individual level for every hazardous substance is neither practical nor cost-effective (Lawrie and Rees 1996), especially when the objective is to verify that a safety limit is not exceeded. As a consequence, dietary exposure should be evaluated through a stepwise approach (WHO 1997).

The stepwise approach follows the premise of an assessment using the least refined method (screening) towards the most refined one, if necessary. The refinement of data is judged necessary when the dietary exposure assessed with a conservative method using highly aggregated data (i.e. the chemical is assumed to be present in specific food groups supposedly ingested by the whole population and there is no information about distribution of the consumption) exceeds the safety limits of the chemical. Once safety limits are surpassed, this indicates there is a possibility of safety concern and further investigation is needed by using less aggregated data (e.g. food consumption collected at the individual level). Then, the next step is performed using more detailed information on food consumption and/or concentration data in order to determine the right hand extreme of the distribution of dietary exposure. On the other hand, when the dietary exposure assessed using screening methods is under the safety limits, further refinement of the assessment is not needed (Gibney and Lambe 1996, Lawrie and Rees 1996, WHO 1997). In this way, wasting of resources by

*Joint Food and Agriculture Organization/World Health Organization 
collecting a large amount of unneeded data is avoided. The most important characteristic of screening methods is that conservative assumptions regarding food consumption and concentration levels in food should be used in order to provide a good level of protection for the whole population by intentionally overestimating chronic dietary exposure (FAO/WHO 2005).

The assessment is said to be refined when dietary exposure evaluations go beyond conservative assumptions of screening methods. In a refined assessment, the purpose of the evaluation often changes to provide an estimate of dietary exposure based on observed food consumption patterns and/or measured chemical concentration data rather than assumed values (EFSA 2006, FAO/WHO 2005). The refinement of dietary exposure to chemicals should be designed in such a way that non-average individuals are considered in the assessment, and in particular those who consume relatively large quantities of foods containing higher concentrations of substances that may potentially lead to a health risk (FAO/WHO 2005).

To consider the distribution of dietary exposure, it is important to collect food consumption information from individuals rather than base the assessment on average population data. Methods available to collect individual dietary data include food records, food frequency questionnaires and 24-hour dietary recalls (Kroes et al. 2002). Monitoring surveys aim to provide such type of information for nationally representative populations. However, dietary assessment methods are not standardized across countries (Verger et al. 2002) and the level of detail available in the data may differ considerably.

Furthermore, challenges may be encountered during refined dietary exposure assessment using information at the individual level. One of these challenges is the presence of uncertainties in the process of identifying and describing the consumption of foods. The nonidentification of potential consumers of interest may occur due to the lack of ability of dietary methods, such as 24-hour dietary recalls, on capturing sufficient information for the assessment of chemicals in the diet (EFSA 2006). Additionally, the ability of interviewees on providing such information can be limited, resulting in misreporting or non-reporting of foods. 
104 The 'European Food Consumption Validation' (EFCOVAL) project aims at validating a method 105 for future monitoring surveys on the dietary intake in European countries. For this purpose, a 106 duplicate 24-hour recall using EPIC-Soft software has been chosen. A secondary objective is 107 to adapt EPIC-Soft in such a way that food safety issues can be investigated. To explore this, 108 the flavouring substances category has been chosen.

109 In this paper, we report the results of an explorative study aimed at comparing methods used 110 to estimate the dietary exposure to flavourings in the context of a stepwise approach. 
111

112

113

114

115

116

117

118

119

120

121

122

123

124

125

126

127

128

129

130

131

132

133

134

135

136

137

138

MATERIAL AND METHODS

\section{Flavourings under investigation}

Four flavourings were selected for the exercise of assessing dietary exposure to flavourings in the diet: raspberry ketone, glycyrrhizinic acid (excluding ammonium glycyrrhizinate), coumarin and caffeine. These flavourings represent different origins (naturally contained in food and/or added flavouring) and different production volumes when used as added flavouring.

Raspberry Ketone (4-(4-Hydroxyphenyl)butan-2-one; Chemical Abstracts Service (CAS) number $5471-51-2)$ is the primary aroma compound of raspberry and is also found naturally in other berry fruits such as cranberry, blackberry, and loganberry (Borejsza-Wysocki 1994, Gallois 1982). It is also used in flavour formulations of mixed berries and strawberries added to processed foods such as yoghurt and beverages (Burdock 2005, Gerasimov 2001). The safety limit for raspberry ketone is assumed to be $0.03 \mathrm{mg} \mathrm{kg}^{-1}$ body weight (bw) day ${ }^{-1}$, considering the Threshold of Toxicological Concern (TTC) of $1800 \mu \mathrm{g}$ person $^{-1}$ day $^{-1}$ for flavourings classified in structural class I (Cramer et al. 1978) and assuming a $60 \mathrm{~kg}$ adult. Structural class I suggests the lowest of three classes of toxicity of flavourings in their safety evaluation procedure by JECFA and was assigned to raspberry ketone in 2001 (WHO 2001).

Glycyrrhizinic acid (CAS number 1405-86-3) is found in foods and beverages as a natural constituent or as an added flavouring. Glycyrrhizinic acid is present in extracts of roots and rhizomes of the Liquorice plant, Glycyrrhiza glabra. Liquorice confectionery and herbal teas are the main sources of dietary exposure to this substance (Fenwick et al. 1990, Stormer et al. 1993). Although an acceptable daily intake (ADI) is not determined, safety evaluations of glycyrrhizinic acid performed by JECFA and the Scientific Committee on Food (SCF) have suggested that a dietary exposure to $100 \mathrm{mg} \mathrm{day}^{-1}$ would be unlikely to cause adverse effects in the majority of adults (SCF 1991, 2003, WHO 2006). A safety factor of 10 has been used by Stormer et al. (1993) to establish a safety limit with the $100 \mathrm{mg} \mathrm{day}^{-1}$ figure. This safety factor is used to account for inter-individual variability in susceptibility when toxicological information is available for humans. Based on this reference, a safety limit of $0.16 \mathrm{mg} \mathrm{kg}^{-1} \mathrm{bw}$ day $^{-1}$, considering a $60 \mathrm{~kg}$ bw was used in the present paper for the sole scope of this study. 
139 Coumarin (1,2-benzopyrone; CAS number 91-64-5) is a naturally occurring flavouring present 140 in plants and spices. The main source of coumarin in the diet is cinnamon (Rychlik 2008) 141 although coumarin content can greatly differ between different types of cinnamon. Cassia 142 cinnamon can contain up to $3000 \mathrm{mg} \mathrm{kg}^{-1}$ of coumarin whereas the most refined type of 143 cinnamon, the Ceylon cinnamon, contains only about $8 \mathrm{mg} \mathrm{kg}^{-1}$ (BfR 2006). Other sources of 144 coumarin include bilberry, celery, and green tea (Felter et al. 2006). According to both EU and 145 USA legislation, coumarin can not be added as such to foodstuffs, whereas it may be present 146 in a foodstuff following the addition of cinnamon. For this reason, maximum permitted levels 147 of coumarin in foodstuffs have been set (European Commission 2008). Furthermore, EFSA 148 suggests a Tolerable Daily Intake (TDI) of $0.1 \mathrm{mg} \mathrm{kg}^{-1}$ bw (EFSA 2004a, EFSA 2008a).

149 Caffeine (1,3,7-trimethylxanthine; CAS number 58-08-2) may be naturally present in foods or 150 added to them. Beverages and foods containing caffeine include coffee, tea, guarana, cola 151 nuts, cocoa, chocolate, energy drinks, and some plants (e.g. mate) (Gilbert 1984). In addition, 152 caffeine may be added to a variety of both prescription and over-the-counter drugs, which 153 were not part of the present assessment. An officially established TDI or ADI for caffeine does 154 not exist. A review published by Nawrot and colleagues (2003), concluded that for the healthy 155 adult population, moderate daily caffeine intake at a dose level up to $400 \mathrm{mg}$ day- 1 was not 156 associated with adverse effects. Thus, for the sole scope of this study, the safety limit to 157 caffeine was estimated to be $6.7 \mathrm{mg} \mathrm{kg}^{-1}$ bw when using an individual bw of $60 \mathrm{~kg}$.

158 Food consumption data used for the refined assessment of dietary exposure

159 Food consumption data used in the refined dietary exposure assessment was collected in the 160 Dutch sample of the EFCOVAL validation study. Between May and July 2007, trained 161 dieticians carried out interviews using a standardized 24-hour dietary recall method (EPIC162 Soft software) on two non-consecutive days. The two 24-hour dietary recalls were collected 163 with at least one month in-between, taking into account weekday variations. The sample 164 consisted of a total of 121 healthy Dutch adults (62 women and 59 men), aged between 45 165 and 65 years old and with all educational levels being represented. However, the participants 166 in the EFCOVAL validation study could not be considered a representative sample of the 167 general population in these strata. The study protocol was approved by the Wageningen 
168 University Ethical Committee and informed consent was obtained from all study participants.

169

170

171

172

173

174

175

176

177

178

179

180

181

182

183

184

185

186

187

188

189

190

191

192

193

194

195

196

\section{EPIC-Soft software}

EPIC-Soft is a software program that has been developed in the EPIC study (European Prospective Investigation into Cancer and Nutrition) to ensure the highest possible level of standardization of 24-hour dietary recalls. The structure and standardization procedure of EPIC-Soft are described in detail elsewhere (Slimani et al. 1999, Slimani et al. 2000). An important feature of EPIC-Soft is the use of two complementary food description systems: explicit and implicit. In the explicit description, facets and descriptors are used during the process of food identification, which is based on the Langual coding system initially used to describe technological and toxicological food characteristics (FDA/CFSAN 1993). Facets are used to describe foods in more detail and this is done by means of standardized questions asked to the interviewee each time a food is reported. One of the facets available for a number of food categories is 'flavour or added component'. The descriptors, which are the country-specific terms associated with each facet, are used as pre-defined potential answers built in the database of the software (e.g. strawberry flavour or strawberry added pieces). In addition, the descriptor 'unknown' may be used when the interviewees are not able to provide the expected level of detail (e.g. unknown flavour for a yogurt that has been consumed). In the implicit description, the name of a food provides sufficient information to identify the food and no further detail is collected using the facet/descriptor system. For instance, the food name "liquorice drops" implies the presence of liquorice so that there is no need to use the facet "flavour" to indicate such presence.

A pre-existing list of facets and descriptors was available in the Dutch software's database since EPIC-Soft has been used in the Dutch National Food Consumption Survey (Ocké et al. 2005). However, this list was not aimed at the assessment of dietary exposure to flavourings. Therefore, within the EFCOVAL study adjustments were made in the list of descriptors and facets for the identification of foods containing raspberry flavouring. The facet 'flavour' was assigned to new food groups where raspberry may be present, and fourteen new descriptors were included: raspberry, blackberry, blueberry, cranberry, strawberry, cloudberry, loganberry, thimbleberry, bilberry, blackberry, mulberry, berries non-specified (n.s.), red fruits 
197

198

199

200

201

202

203

204

205

206

207

208

209

210

211

212

213

214

215

216

217

218

219

220

221

222

223

224

n.s., forest fruit. No further adaptations were made in the descriptors of glycyrrhizinic acid (i.e. liquorice), caffeine (i.e. coffee) and coumarin (i.e. cinnamon) flavourings.

\section{Dietary exposure assessment}

With the use of the stepwise approach, dietary exposure to the four flavourings was assessed in three different steps (Table 1).

$\underline{\text { Step } 1}$ - Use of screening methods: Maximized Survey-Derived Daily Intake (MSDI) and Single-Portion Exposure Technique (SPET) as used by JECFA and modified Theoretical Added Maximum Daily Intake (mTAMDI) used by EFSA.

$M S D I$ is also known as the 'per capita method' or 'per capita $\times 10$ ' approach. Assumptions of the method are: that $60 \%$ of total production of flavourings is reported by the industry; that $10 \%$ of the total population are consumers of the flavouring; and that there is no variation in the intake of the particular flavouring among consumers. Accordingly, the following formula is used:

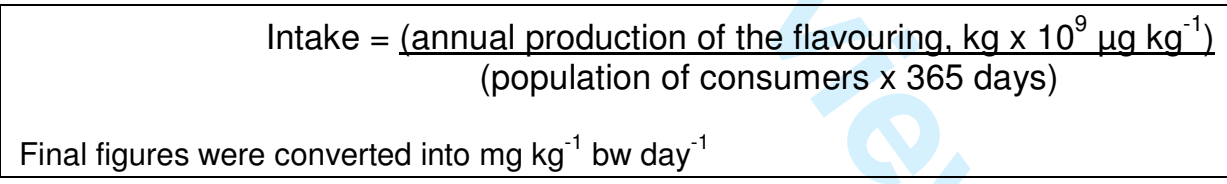

As for the safety evaluations performed by JECFA, EU population in this study was assumed to be $32 \times 10^{6}$. The annual production volumes of the flavourings considered were those used by JECFA (WHO 2001) and SCF (SCF 2003): $19.500 \mathrm{~kg} \mathrm{y}^{-1}$ for raspberry ketone and 1.956 $\mathrm{kg} \mathrm{y}^{-1}$ for glycyrrhizinic acid, respectively. Poundage data for coumarin is not available since it can not be used as an added flavouring substance. In the absence of EU production volumes for caffeine, per capita dietary exposure in the USA was used as a proxy for per capita dietary exposure in the EU.

The SPET method provides a dietary exposure assessment based on normal use levels and identifies the single food category containing the flavouring agent of interest that is likely to contribute to the highest dietary exposure from one 'standard portion'. The standard portion is taken to represent the mean food consumption amount within one eating event for consumers 
of that food category, assuming daily consumption of one portion over a long period. These standard portions can be found in the 67th and 69th report of JECFA (WHO 2007, WHO 2009). Thus, the general formula to derive the SPET figure is:

Intake $\left(\mathrm{mg} \mathrm{kg}^{-1}\right)=$ Maximum (standard portion size $(\mathrm{mg}) \times$ normal use level of the flavouring $(\mathrm{mg} / \mathrm{kg}))$

The industry normal use levels used in this study were the ones reported in the Fenaroli's handbook (Burdock 2005), except for glycyrrhizinic acid, for which only upper use levels are reported by industry (EFFA 2003). For coumarin, the maximum permitted level in foods containing cinnamon (European Commission 2008) was used as replacement of the absent upper use level.

mTAMDI is calculated on the basis of standard portions and normal use levels for flavourable beverages and foods in general, i.e. foods and beverages that may contain the flavouring substance, and for five particular foods groups (exceptions a to e). For instance, exception used in this calculation refers to candies and confectioneries (EFSA 2004b). The use levels considered for SPET calculations were also applied to calculate mTAMDI. The general formula used to estimate the mTAMDI (EFSA 2004b) is:

Because literature has shown that observed levels of coumarin in food products containing cinnamon can be in fact higher than the maximum permitted level (BfR 2006), further screening calculations were made to assess the dietary exposure to coumarin by considering the observed coumarin content in cinnamon products. Therefore, extra calculations of SPET and mTAMDI were done with use levels of cinnamon as reported by the Flavour and Extract 
255 amounts in two types of cinnamon (cassia cinnamon: $0.3 \%$; Ceylon cinnamon: $0.008 \%$ (BfR 256 2006)).

257 Step 2 - Use of food consumption data aggregated in food groups.

258 At this step, food consumption data at the individual level (Dutch EFCOVAL sample) were 259 grouped in food categories based on the EPIC-Soft grouping system (Slimani, et al. 1999). It 260 was assumed that all foods within a given 'flavourable food category' contained the flavouring 261 of interest (see Appendix 1). For instance, raspberry ketone may be added to some foods in 262 the dairy food group (e.g. yogurts). Thus, in the assessment of step 2, all foods belonging to 263 the yogurt category, a subgroup category of dairy products, were assumed to contain 264 raspberry ketone, even though some foods are known not to contain it.

265 Concentration levels used in step 2 were called 'refined concentrations' (see Appendix 2).

266 First choice for the concentration data was normal use levels reported by industry. An 267 exception was made for caffeine contents in non-alcoholic beverages since reported industry 268 levels $(0.13 \mathrm{mg} / \mathrm{kg})$ were clearly underestimated as compared to the analytical determinations 269 gathered in the literature (see Appendix 2). For glycyrrhizinic acid, upper use levels were 270 used. Analytical determinations from literature were also used in the cases where the 271 flavouring was known to occur in its natural form or when levels of added flavourings were not 272 reported by industry. For instance, glycyrrhizinic acid is known to be added to soy sauce, but 273 use levels in sauces have not been reported. List of references used to collect the flavouring 274 concentration data in foods can be provided upon request.

275 Step 3 - Use of food consumption data at the level of foods items.

276 Within this step, three models were created based on the consumption of food items from the 277 Dutch EFCOVAL sample. The first two models ( $3 a$ and $3 b$ in Table 1) considered the 278 consumption of foods that, according to the name of the product or to the use of facets and 279 descriptors available in EPIC-Soft, do contain the flavouring. The difference between the two 280 steps was that step $3 \mathrm{~b}$ included information from flavourings after the descriptors of the facet 281 flavour had been extended (for the assessment of raspberry ketone only) in the EFCOVAL 


\begin{abstract}
282 study, while step 3a gave information that would have been available before the extension. In 283 the last of the three models (3c), foods were identified in the same way as for step $3 a$ (for 284 glycyrrhizinic acid, caffeine and coumarin) and 3b (for raspberry ketone), but the descriptor 285 'unknown flavour' was assumed to include the flavouring of interest.
\end{abstract}

286 Concentration levels used in step 3 were the same as used in step 2: 'refined concentration'.

\title{
Data analysis
}

288 To estimate dietary exposure to the flavourings, food consumption was multiplied by the 289 concentration of the chemical in the food and then divided by the body weight to be 290 expressed in $\mathrm{mg} \mathrm{kg}^{-1}$ bw day ${ }^{-1}$. In step 1, a body weight of 60 kilos was assumed whereas for 291 steps 2 and 3, individually measured body weights were used. Food consumption data in 292 steps 2 and 3 were based, for each individual, on the average of the two 24-hour dietary 293 recalls. In these two steps, potential dietary exposure to the flavourings was estimated for 294 each subject. Besides the mean and the median intake of the total group, the $95^{\text {th }}$ percentile 295 of the population distribution was used to characterize highly exposed subjects. As stated by 296 EFSA (2008b), the 95th percentile can be assessed with approximately 130 subjects when 297 using a binominal distribution (Conover 1971). Furthermore, the average contribution of the 298 different food groups to the overall dietary exposure in steps 2 and 3 was estimated in 299 percentages. Data processing and descriptive statistical analyses were performed using SAS 300 software (version 9.1; SAS Institute, Cary NC, USA). 
301

302

303

304

305

306

307

308

309

310

311

312

313

314

315

316

317

318

319

320

321

322

323

324

325

326

327

328

\section{RESULTS}

All three screening methods (Step 1) provided exposure estimates at or over the safety limit for raspberry ketone and, therefore, further refinement of the dietary exposure assessment was needed for this flavouring (Table 2). For glycyrrhizinic acid, the MSDI method indicated a dietary exposure at least 16 times lower than the safety limit, whereas the two other methods (SPET and mTAMDI) provided estimates above the safety limit, indicating the need of refinement. Caffeine presented an estimate above the safety limit based on the MSDI method. Additional refinement of coumarin dietary exposure was not necessary based on the screening methods. However, dietary exposure assessment of coumarin using models of step 2 and 3 was carried out given that the four selected flavourings were meant to be examples for practical testing of dietary exposure assessment through the use of EPIC-Soft.

Descriptive analyses of dietary exposure assessment using highly aggregated consumption data at the food group level are presented in Table 3 (step 2). Average and high $\left(95^{\text {th }}\right.$ percentile) levels of exposure to raspberry ketone, glycyrrhizinic acid and caffeine were above the safety limit, indicating the need for more detailed assessment of these three flavourings. Average dietary exposure to coumarin was below the safety limit, despite of the conservative model on food consumption used in Step 2, but above the safety limit at the $95^{\text {th }}$ percentile. Therefore, additional investigation of dietary exposure to coumarin was necessary within the stepwise approach.

Table 3 also presents results of the dietary exposure done at the food item level (step 3 ). When identifying foods by the name of the product and without using the extended facets and descriptors (step 3a), the mean dietary exposure was under the safety limits, except for caffeine ( $\cong$ eight times higher). At the $95^{\text {th }}$ percentile, the dietary exposure to glycyrrhizinic acid and caffeine were three and twenty times higher than the safety limit, respectively. In the case of raspberry ketone, if considering the adjustments made in the database for facets and descriptors (step 3b), dietary exposure was higher than values obtained in step 3a. In the next step (3c), when not only foods that surely contained the flavouring substance were included in 


\begin{abstract}
329 mean dietary exposure to raspberry ketone and glycyrrhizinic acid was slightly higher as 330 compared to step $3 \mathrm{a}$ and $3 \mathrm{~b}$. In the case of coumarin and caffeine, dietary exposure was the 331 same in all of these steps.
\end{abstract}

By comparing tables 2 and 3 it appears that in some cases the screening techniques lead to a 333 dietary exposure lower than that of the refined exposure assessment. It was the case for 334 raspberry ketone where SPET was $0.03 \mathrm{mg} / \mathrm{kg}$ versus 0.04 and $0.05 \mathrm{mg} / \mathrm{kg}$ at the $95^{\text {th }}$ 335 percentile at step $3 b$ and $3 c$, respectively.

336 In the investigation of food groups contributing to the exposure in each step of the 337 assessment (Figure 1), it can be seen that for raspberry ketone the main sources of the 338 flavourings were the same in almost all steps: 'dairy products' and 'non-alcoholic beverages'. 339 Yet, while 'non-alcoholic beverages' and 'cakes' were the food groups most contributing to the 340 dietary exposure of raspberry flavouring in step 3a, dietary exposure to raspberry contained in 341 'dairy products' became an important source with the use of facets and descriptors in step 3b. 342 In the case of glycyrrhizinic acid, 'sugar and confectionery' and 'non-alcoholic beverages' 343 (most herbal teas) were the bigger contributors of the substance in all steps, with a probable 344 overestimation of the contribution from 'sugar and confectionery' in step 2 (group level) as 345 compared to the other steps. The same pattern of overestimation at food group level is seen 346 in the assessment of coumarin and caffeine (figures not shown). Main contributors to dietary 347 exposure were 'cakes', 'biscuits' and 'tea' for coumarin and 'non-alcoholic beverages' for 348 caffeine at all steps. 
349

350

351

352

353

354

355

356

357

358

359

360

361

362

363

364

365

366

367

368

369

370

371

372

373

374

375

376

377

\section{DISCUSSION}

The dietary exposure to raspberry ketone, glycyrrhizinic acid, coumarin and caffeine was estimated in this study using a stepwise approach. It has been shown that the refinement of food consumption data in the assessment of dietary exposure to flavourings might be necessary, but dependent of the chosen screening method for the assessment. When using data from the $24 \mathrm{~h}$-dietary recall by means of EPIC-Soft software, the dietary exposure to raspberry ketone was higher in the model where descriptors have been extended as compared to the model where no adjustments have been considered.

The dietary exposure calculated using the screening methods exceeded the safety limits and therefore implied the need of more refined assessment for raspberry ketone, glycyrrhizinic acid and caffeine, but with somewhat different results depending on the method used and on the flavouring under assessment. In particular, variation in outcomes using different screening methods was observed; whereas by the MSDI method the exposure to glycyrrhizinic acid was evaluated to be of no safety concern, the dietary exposure assessed by SPET and mTAMDI indicated the need of further refinement. On the other hand, dietary exposure to caffeine assessed by MSDI indicated the need of refined assessment while the other two methods did not indicate it. One of the reasons for the variation in results from the screening methods is probably the difference in assumptions between them (e.g. the percentage of consumers in the dietary exposure and how conservative they are, i.e. whether individuals, who consume large quantities of flavoured foods, are considered in the dietary exposure assessed by the different methods). Although it is beyond the scope of this study to investigate the accuracy of such estimates, this topic deserves further attention. In fact, many of the conservative assumptions and default values that are currently used in screening assessments were established some time ago and in some cases they were originally based on subjective or arbitrary estimates (EFSA 2006). In the case of the MSDI, which until recently was the unique method used by JECFA to assess dietary exposure within the safety evaluation of flavourings, the insufficient conservativeness of the method has been discussed in a number of scientific publications (Arcella and Leclercq 2005, Hall and Ford 1999, Lambe et al. 2002, Leclercq 2007, Munro and Danielewska-Nikiel 2006). Most recently, JECFA has acknowledged the 
378

likely underestimation of the MSDI method in the assessment of some flavourings and developed a new method (SPET), which takes into account different food patterns of consumers and the uneven distribution of dietary exposure in consumers of flavourings (WHO 2007). Furthermore, according to EFSA, the appropriateness of the conservative assumptions and default values that are used in screening assessments of chemicals, including flavourings may require further investigation. Analysis of uncertainty in the screening assessment may not be required, provided they include proper conservative assumptions to take account of uncertainty (EFSA 2006).

Once the need of further refinement in the dietary exposure is identified, other limitations might be encountered in the assessment of exposure to chemicals in the diet. For instance, the knowledge of chemical concentration data in foods is limited and the ability of dietary methods to assess dietary exposure to chemicals can be uncertain. In our study, this last issue has been explored through the different models created to assess the dietary exposure to flavourings in the Dutch population.

In the first model created (step 2), the dietary exposure was characterized by investigating the consumption of flavourings at the food group level. As noted in Table 3, the dietary exposures of the four flavourings were high as compared to all other steps of the assessment. Considering that in this model, foods that do not contain the flavouring may have been quantified as part of the dietary exposure, we recognize a certain degree of overestimation in the estimate. This should be, however, an indication of safe dietary exposure, in case the estimate would be below the safety limit. However, the need for further refinement of the food consumption data collected at the individual level appeared necessary for the four flavourings under assessment.

With the data on food items collected with the 24-hour dietary recall, it has been noted that the adjustments made in the software databases for the raspberry ketone case, resulted in a higher dietary exposure to this flavouring. The number of consumers in step $3 b$, where the new raspberry ketone descriptors have been included, was eight times higher as compared to the step with no modifications in EPIC-Soft (data not shown). This is the result of food consumption data collected at lower aggregation level and with more details. Assuming that 
the 24-hour dietary recall provided an accurate estimate of the intake of flavoured foods, the high dietary exposure to raspberry ketone in step $3 b$ suggests that such adjustments, which characterize the consumption of foods in more detail, is useful when assessing dietary exposure to flavourings. Nonetheless, 24-hour dietary recalls are known to underestimate the

No alterations in the Dutch EPIC-Soft version were implemented for glycyrrhizinic acid, coumarin and caffeine, and evaluation of such alterations was therefore not possible. However, for some types of flavourings, such as glycyrrhizinic acid, the use of facets and descriptors might not be that important for an accurate dietary exposure assessment given that the food name itself often indicates the presence of the flavouring, which would be enough for the food identification. Nevertheless, additional exploration is needed for this conclusion. Moreover, we do not know to what extent the consumption of cinnamon was correctly identified. First, the use of spices, including cinnamon, during home cooking is not collected during the 24-hour dietary recall using Epic-Soft software. Second, this spice, in particular, may not be easily identified by the name of the product and neither by the use of descriptors since it does not seem to be clear to the population whether a certain food would contain cinnamon or not. The dieticians of our study reported that for the food group most expected to contain cinnamon (cereals and biscuits), subjects were not able to provide this kind of detail and that they, as interviewers, had no experience in collecting information about flavourings. Third, the authors of this study may have been not correctly identified the presence of cinnamon in certain culinary products such as soups since the presence of cinnamon is not always evident. Because of these reasons, the dietary exposure to coumarin may have been underestimated in this assessment. As a check whether the descriptors of the four flavourings may have been sufficiently identified, the potential flavoured foods with descriptor 'non-specified' were assumed to include the flavouring of interest (Step 3c). The dietary exposure did not considerably change for any of the four flavourings in this step.

435 The assessment of dietary exposure by the different steps and their food group sources gives 
436 an indication that such changes in the database (in facets and descriptors) may be food group 437 dependent. Most probable, some degree of uncertainty was present in the assessment at 438 food group level, which tends to overestimate the dietary exposure to flavourings. When the 439 need of more detailed dietary exposure assessment to a specific flavour is identified, the 440 more detailed approach could be limited to a number of food groups, for which it is known that 441 the flavouring can be present and descriptors should be added.

442 It is important to mention that the estimates presented in steps 2 and 3 of the assessment are 443 not representative of the usual Dutch food consumption. Because of the lack of 444 representativeness of the sample and the limited number of survey days, chronic dietary 445 exposure may not have been correctly estimated in this assessment. In fact, the collection of 446 only two days of 24-h recalls does not allow to assess chronic exposure but short term 447 exposure. This is probably the reason why the refined exposure assessment performed for 448 raspberry ketone leads to higher values than that obtained with the SPET technique. An 449 improved refined assessment could be performed by using additional information on usual 450 intake of flavoured foods, such as a food propensity questionnaire. Subar and colleagues 451 (2006) have shown that food propensity questionnaires may offer important covariate 452 information in supplementing $24-\mathrm{h}$ recalls for estimating usual intake of food groups. This is 453 possibly true for assessing chemicals in the diet as well. Furthermore, only dietary exposure 454 has been considered in our assessment and contribution from other sources (e.g. medicines) 455 may lead to an additional exposure. In fact, the safety limits we have used in this 456 assessment should refer to the total exposure to the flavourings but with the study we 457 performed we can only conclude on exposure from the diet. In addition, the small number of 458 evaluated flavourings limits the possibilities to extrapolate the results of our study to other 459 types of flavourings. Another limitation is the scarce availability of concentration data on 460 chemicals. These are relatively seldom published in open literature and therefore difficult to 461 retrieve(EFSA 2005). In the flavouring case, few analytical data are currently available and 462 little is know about the influence of storage and processing on the residues of theses 463 substances in food (EFSA 2006). Consequently, a high variability in the available 464 concentration data is expected.. This study, however, was a first exploration of the possibilities to assess dietary exposure to food chemicals by using data collected at the 
466 individual level with the standardized 24 -h recall.

467 In summary, this study showed that the collection of detailed food consumption data at the

468 individual level is useful and should be further explored for other flavourings. In addition, the 469 possibility of further adaptations of the databases used in EPIC-Soft software seemed to 470 provide a higher dietary exposure to raspberry ketone as compared to the non-modified 471 databases, which may also be true for other flavourings. Yet, the need for alterations may still 472 differ depending on the nature of the flavouring under assessment. To further study the 473 usefulness of detailed food consumption data in the dietary exposure assessment of 474 flavourings and other chemicals, research should include biological markers and analytical 475 determination in flavoured foods, which would warrant the check of accuracy of such 476 estimates. Finally, the benefit of assessing usual intake of chemicals in the diet by combining 477 24-h recalls and food propensity questionnaires is a topic that deserves more exploration. 
480

481

482

483

484

485

486

487

488

489

490

491

492

493

494

495

496

497

498 Norway

499 Spain

500 United Kingdom

501

502

503

504

505

Belgium

Croatia

Czech Republic

Denmark

France

\section{ACKNOWLEDGMENTS}

The Community funding under the Sixth Framework Program for the EFCOVAL project is acknowledged (FOOD-CT-2006-022895). Authors wish to thank Davide Arcella (EFSA) and EFCOVAL partners for their useful advices.

This document reflects only the author's views and the Community is not liable for any use that may be made of the information contained therein.

\section{EFCOVAL partners}

Ghent University (DPH)

Academy of Medical Sciences (AMZH)

National Institute of Public Health (NIPH)

National Institute, Technical University of Denmark (DTU)

French Food Safety Authority (AFSSA)

International Agency for Research on Cancer (IARC)

National Institute for Agricultural Research (INRA)

German Institute of Human Nutrition (DIfE)

National Research Institute for Food and Nutrition (INRAN)

Wageningen University (WU)

National Institute for Public Health and the Environment (RIVM)

University of Oslo

Basque Foundation for Health Innovation and Rsearch (BIOEF)

Prima informatics limited (Primainfo) 
506

507

508

509

510

511

512

513

514

515

516

517

518

519

520

521

522

523

524

525

526

527

528

529

530

531

532

533

534

535

536

\section{REFERENCES}

Arcella D and Leclercq C. 2005. Assessment of dietary intake of flavouring substances within the procedure for their safety evaluation: advantages and limitations of estimates obtained by means of a per capita method. Food Chem Toxicol. 43(1):105-116.

BfR. 16 June 2006. Consumers, who eat a lot of cinnamon, currently have an overly high exposure to coumarin. Federal Institute for Risk Assessment. BfR Health Assessment No. 043/2006. Berlin (Germany).

Bingham S. 1987. The dietary assessment of individuals; methods, accuracy, new techniques and recommendations. Nutrition Abstracts and Reviews. 9(1).

Borejsza-Wysocki W. 1994. Biosynthesis of p-hydroxyphenylbutan-2-one in raspberry fruits and tissue cultures. Phytochemistry (Oxford). 35(3):623-628.

Burdock GA. 2005. Fenaroli's handbook of flavor ingredients. 5th ed. Florida (US): CRC Press.

Conover WJ. 1971. Practical Nonparametric Statistics. New York: Wiley.

Cramer GA, Ford RA and Hall RL. 1978. Estimation of toxic hazard-a decision tree approach. Food Cosmet Toxicol. 16(3):255-276.

EFFA. 2003. European Flavour and Fragrance Association (EFFA). Submission to the European Commission, February 20th, 2003 [document number unknown].

EFSA. 2004a. Opinion of the Scientific Panel on food additives, flavourings, processing aids and materials in contact with food (AFC) related to Coumarin. European Food Safety Authority. EFSA-Q-2003-118. The EFSA Journal. 104:1-36.

EFSA. 2004b. Opinion of the Scientific Panel on Food Additives, Flavourings, Processing Aids and Materials in contact with Food (AFC) on a request from the Commission related to Flavouring Group Evaluation 3 (FGE.03): Acetals of branched- and straight-chain aliphatic saturated primary alcohols and branched- and straight-chain saturated aldehydes, and an orthoester of formic acid, from chemical groups 1 and 2. Question number EFSA-Q-2003-146. The EFSA Journal. 107:1-59.

EFSA. 2005. Opinion of the Scientific Committee on a request from EFSA related to Exposure Assessments. European Food Safety Authority. EFSA-Q-2003-107. The EFSA Journal. 249:1-26.

EFSA. 2006. Guidance of the Scientific Committee on a request from EFSA related to 
537

538

539

540

541

Uncertainties in Dietary Exposure Assessment. European Food Safety Authority. EFSA-Q2004-019. The EFSA Journal. 438:54.

EFSA. 2008a. Coumarin in flavourings and other food ingredients with flavouring properties Scientific Opinion of the Panel on Food Additives, Flavourings, Processing Aids and Materials in Contact with Food (AFC)(Question No EFSA-Q-2008-677) Adopted on 8 July 2008. The EFSA Journal. 793:1-15.

EFSA. 2008b. Guidance document for the use of the Concise European Food Consumption Database in Exposure Assessment, Parma, EFSA/DATEX/2008/01. The EFSA Journal:1-8.

EFSA. 2009. Flavouring Group Evaluation 18, Revision 1 (FGE. 18 Rev1):Aliphatic, alicyclic and aromatic saturated and unsaturated tertiary alcohols, aromatic tertiary alcohols and their esters from chemical groups 6 and 8. European Food Safety Authority. EFSA-Q-2003-150B. The EFSA Journal. 978:1-85.

European Commission. 1999. Commission Decision 1999/217/EC of 23 February 1999 adopting a register of flavourings substances used in or on foodstuffs drawn up in application of Regulation (EC) No 2232/96 of European Parliament and of the Council of 28 October 1996. In: Off J Eur Comm. p. 1-137.

European Commission. 2002. Commission Decision 2002/113/EC of 23 January 2002 amending Commission Decision 1999/217/EC as regards the register of flavouring substances used in or on foodstuffs. In: Off J Eur Comm. p. 1-160.

European Commission. 2004. Commission Decision of 7 April 2004 amending Decision 1999/217/EC as regards the register of flavouring substances. In: Off J Eur Comm. p. 28-36.

European Commission. 2005. Commission Decision of 18 May 2005 amending Decision 1999/217/EC as regards the register of flavouring substances used in or on foodstuffs. In: Off J Eur Comm. p. 73-76.

European Commission. 2008. Regulation (EC) No 1334/2008 of the European Parliament and of the council of 16 December 2008 on flavourings and certain food ingredients with flavouring properties for use in and on foods and amending Council Regulation (EEC) No 1601/91, Regulations (EC) No 2232/96 and (EC) No 110/2008 and Directive 2000/13/EC. In: Off J Eur Comm. p. 34-50.

Fabech B, Bryhni K, Forshell LP, Georgsson F, Gry J, Hansen BT, Hallström H, Hatakka M, Holene E, Kapperud G, Kristinsson J, Maijala R, Nielsen NL, Nordström U, Schultz AC, Solheim $C$ and Thorkelsson ÀE. Date. A practical approach to the application of the risk analysis process - Illustrated with two examples Caffeine and Campylobacter [internet]. cited 2009

Sep 15. Journal:[place unknown].Available from: 
571

572

573

574

575

576

577

578

579

580

581

582

583

584

585

586

587

588

589

590

591

592

593

594

595

596

597

598

599

600

601

http://www.norden.org/da/publikationer/publikationer/2002-510/at download/publicationfile

FAO/WHO. 2005. Consultations and workshops : dietary exposure assessment of chemicals in food : report of a joint FAO/WHO consultation, 2-6 May 2005. Annapolis, Maryland (USA): FAO/WHO.

FDA/CFSAN. 1993. LanguaL User's Manual. version 1993.

Felter SP, Vassalo JD, Carlton BD and Daston GP. 2006. A safety assessment of coumarin taking into account species-specificity of toxicokinetics. Food Chem Toxicol. 44(4):462-475.

Fenwick GR, Lutomski J and Nieman C. 1990. Liquorice, Glycyrrhiza glabra L. - composition, uses and analysis. Food Chem. 38(2):119-143.

Gallois A. 1982. Rapid determination of p-hydroxyphenyl-1-butanone-3 in raspberries by TLC. Sciences des Aliments. 2(1):99-106.

Gerasimov AV. 2001. Application of planar chromatography with computer processing of chromatograms to the analysis of flavoring materials, using the determination of $4-(n-$ hydroxyphenyl)-2-butanone (raspberry ketone) as an example. Zhurnal Analiticheskoi Khimii. 56(4):419-424.

Gibney MJ and Lambe J. 1996. Estimation of food additive intake: methodology overview. Food Addit Contam. 13(4):405-410.

Gilbert RM. 1984. Caffeine consumption. In: The Methylxanthine beverages and foods: Chemistry, consumption, and health effects Berlin (GE): Spring Verlag. p. 185-213.

Hall RL and Ford RA. 1999. Comparison of two methods to assess the intake of flavouring substances. Food additives and contaminants. 16(11):481-495.

Kroes R, Muller D, Lambe J, Lowik MR, van Klaveren J, Kleiner J, Massey R, Mayer S, Urieta I, Verger P and Visconti A. 2002. Assessment of intake from the diet. Food Chem Toxicol. 40(2-3):327-385.

Lambe J, Cadby P and Gibney M. 2002. Comparison of stochastic modelling of the intakes of intentionally added flavouring substances with theoretical added maximum daily intakes (TAMDI) and maximized survey-derived daily intakes (MSDI). Food Addit Contam. 19(1):2-14.

Lawrie CA and Rees NM. 1996. The approach adopted in the UK for the estimation of the intake of food additives. Food Addit Contam. 13(4):411-416.

Leclercq C. 2007. Issues arising when methods used to assess dietary exposure to flavouring substances are compared. Food Chem Toxicol. 45(11):2336-2337. 
Munro IC and Danielewska-Nikiel B. 2006. Comparison of estimated daily intakes of 603 flavouring substances with no-observed-effect levels. Food Chem Toxicol. 44(6):758-809.

604 Nawrot P, Jordan S, Eastwood J, Rotstein J, Hugenholtz A and Feeley M. 2003. Effects of 605 caffeine on human health. Food Addit Contam. 20(1):1-30.

606 Ocké M, Hulshof $\mathrm{K}$ and van Rossum C. 2005. The Dutch national food consumption survey 607 2003. Methodological issues. Archives of Public Health. 63:227-241.

608 Rychlik M. 2008. Quantification of Free Coumarin and Its Liberation from Glucosylated 609 Precursors by Stable Isotope Dilution Assays Based on Liquid Chromatography-Tandem 610 Mass Spectrometric Detection. Journal of Agricultural and Food Chemistry. 56(3):796-801.

611 SCF. 1991. Scientific Committee for Food. Report (29th series). Commission of the European 612 Communities, Food Science and Techniques. SCF/CS/ADD/FLAV/61final. Luxembourg: 613 Office of Official Publications of the EC.

614 SCF. 2003. Opinion of the Scientific Committee on Food on glycyrrhizinic acid and its 615 ammonium salt. SCF/CS/ADD/EDUL/225. In:

616 Luxembourg: Office of Official Publications of the EC. p. 41.

617 Slimani N, Deharveng G, Charrondiere RU, van Kappel AL, Ocke MC, Welch A, Lagiou A, 618 van Liere M, Agudo A, Pala V, Brandstetter B, Andren C, Stripp C, van Staveren WA and 619 Riboli E. 1999. Structure of the standardized computerized 24-h diet recall interview used as 620 reference method in the 22 centers participating in the EPIC project. European Prospective 621 Investigation into Cancer and Nutrition. Comput Methods Programs Biomed. 58(3):251-266.

622 Slimani N, Ferrari P, Ocke M, Welch A, Boeing H, Liere M, Pala V, Amiano P, Lagiou A, 623 Mattisson I, Stripp C, Engeset D, Charrondiere R, Buzzard M, Staveren W and Riboli E. 2000. 624 Standardization of the 24-hour diet recall calibration method used in the european prospective 625 investigation into cancer and nutrition (EPIC): general concepts and preliminary results. Eur $\mathrm{J}$ 626 Clin Nutr. 54(12):900-917.

627 Stormer FC, Reistad R and Alexander J. 1993. Glycyrrhizic acid in liquorice - evaluation of 628 health hazard. Food Chem Toxicol. 31(4):303-312.

629 Subar AF, Dodd KW, Guenther PM, Kipnis V, Midthune D, McDowell M, Tooze JA, Freedman 630 LS and Krebs-Smith SM. 2006. The Food Propensity Questionnaire: Concept, Development, 631 and Validation for Use as a Covariate in a Model to Estimate Usual Food Intake. Journal of 632 the American Dietetic Association. 106(10):1556-1563.

633 Verger P, Ireland J, Møller A, Abravicius J, De Henauw S and Naska A. 2002. Improvement 634 of comparability of dietary intake assessment using currently available individual food 
635 consumption surveys. European Journal of Clinical Nutrition. 56(2):S18-S24.

636 WHO. 1997. Food Consumption and Exposure Assessment of Chemicals. WHO/FSF/FOS/97

637 5. Geneva (Switzerland): FAO/WHO.

638 WHO. 2001. Safety evaulation of certain food additives and contaminants. Prepared by the 639 fifth five meeting of the Joint FAO/WHO Committee on Food Additives (JECFA). WHO 640 Technical report series (901). Geneva (Switzerland): WHO.

641 WHO. 2006. Safety evaluation of certain food additives and contaminants. Prepared by the 642 sixty-three meeting of the Joint FAO/WHO Expert Committee on Food Additives (JECFA). 643 WHO technical report series (54). Geneva (Switzerland): WHO.

644 WHO. 2007. Safety evaluation of certain food additives and contaminants. Prepared by the 645 sixty-seventh meeting of the Joint FAO/WHO Expert Committee on Food Additives (JECFA). 646 WHO technical report series (940) 2006. Rome (Italy): WHO.

647 WHO. 2009. Evaluation of certain food additives. Prepared by the sixty-ninth meeting of the 648 Joint FAO/WHO Expert Committee on Food Additives (JECFA). WHO technical report series 649 (952) 2008. Rome (Italy): WHO.

650 Willett W. 1998. Nutritional epidemiology. New York: Oxford University Press.

651

652 
Table 1 - Stepwise approach used for the assessment of dietary exposure to flavourings in the EFCOVAL study

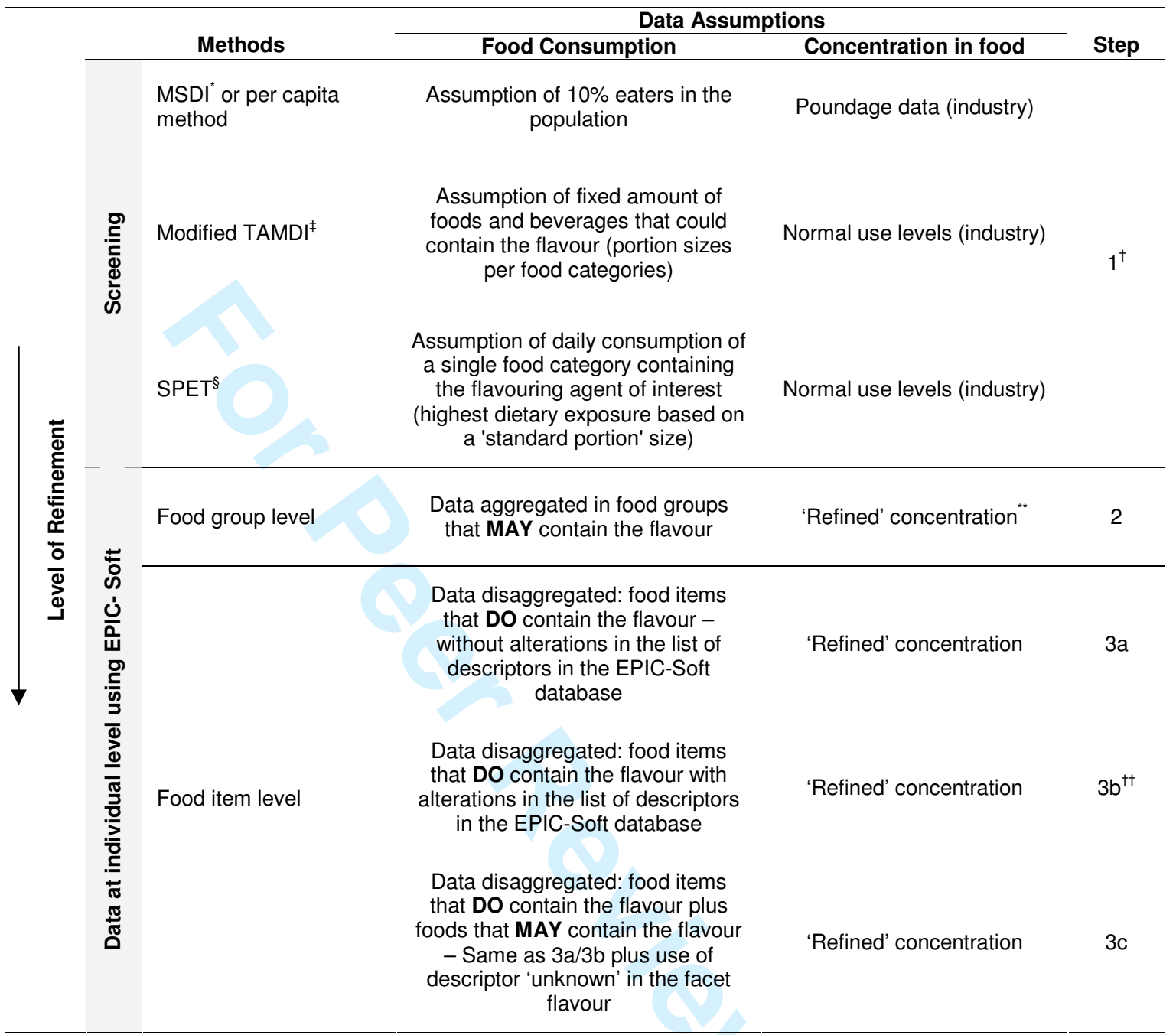

\footnotetext{
"Maximized Survey-Derived Daily Intake

${ }^{\dagger}$ Dietary exposure is expressed in $\mathrm{mg} \mathrm{kg}^{-1}$ bw day $^{-1}$, considering an individual weighing $60 \mathrm{~kg}$

${ }^{\ddagger}$ Modified Theoretical Added Maximum Daily Intake

$\S$ Single-Portion Exposure Technique

"Concentration values from industry (normal use levels) and analytical determinations found in the literature

${ }^{\mathrm{t \dagger}}$ For raspberry ketone only
} 


\begin{tabular}{|c|c|c|c|c|c|c|c|}
\hline \multirow[t]{3}{*}{ Flavouring } & \multirow[t]{3}{*}{ Safety limit } & \multicolumn{6}{|c|}{ Screening method ${ }^{\top}$} \\
\hline & & \multicolumn{2}{|c|}{ MSDI } & \multicolumn{2}{|c|}{ SPET } & \multicolumn{2}{|c|}{ mTAMDI } \\
\hline & & $\begin{array}{l}\text { Production } \\
\text { volume }\end{array}$ & $\begin{array}{c}\text { Dietary } \\
\text { Exposure }\end{array}$ & $\begin{array}{l}\text { Concentration } \\
\text { source }\end{array}$ & $\begin{array}{c}\text { Dietary } \\
\text { Exposure }\end{array}$ & $\begin{array}{l}\text { Concentration } \\
\text { source }\end{array}$ & $\begin{array}{c}\text { Dietary } \\
\text { Exposure }\end{array}$ \\
\hline Raspberry ketone & 0.03 & $|\mathrm{IOF}|^{\ddagger}$ & 0.05 & FEMA $^{\S}$ & 0.03 & FEMA & 0.06 \\
\hline Glycyrrhizinic acid & 0.16 & $\mathrm{EFFA}^{* *}$ & $<0.01$ & EFFA & 3.3 & EFFA & 3.5 \\
\hline $\begin{array}{l}\text { Coumarin } \\
\text {-from Cassia cinnamon } \\
\text {-from Ceylon cinnamon }\end{array}$ & 0.10 & $\begin{array}{l}- \\
- \\
-\end{array}$ & $\begin{array}{l}- \\
- \\
-\end{array}$ & $\begin{array}{l}\text { EU legislation }{ }^{\dagger \dagger} \\
\text { FEMA } \\
\text { FEMA }\end{array}$ & $\begin{array}{c}0.05 \\
0.03 \\
<0.01\end{array}$ & $\begin{array}{l}\text { EU legislation } \\
\text { FEMA } \\
\text { FEMA }\end{array}$ & $\begin{array}{l}0.02 \\
0.04 \\
<0.01\end{array}$ \\
\hline Caffeine & 6.7 & FEMA & $7.3^{\circ}$ & FEMA & $<0.01$ & FEMA & $<0.01$ \\
\hline
\end{tabular}

"Raspberry ketone: Threshold of Toxicological Concern in relation to structural class I (Cramer, et al. 1978); Glycyrrhizinic acid: Provisional LOAEL, (SCF 2003); Coumarin: Tolerable Daily Intake (EFSA 2004b); Caffeine: Tolerable daily intake (Fabech, et al. 2002)

${ }^{+}$MSDI: Maximized Survey-Derived Daily Intake; SPET: Single-Portion Exposure Technique; mTAMDI: modified Theoretical Added Maximum Daily Intake

¥ International Organisation of Flavour Industry.

${ }_{\star *}$ Flavour and Extract Manufacturers' Association (US).

European Flavour and Fragrance Association.

${ }^{\mathrm{tt}}$ Use of maximum permitted levels instead of absent use levels.

- In the absence of EU production volumes for caffeine, per capita dietary exposure in the USA (based on USA production volumes) was used as a proxy for per capita dietary exposure in the EU 
Table 3 - Estimated dietary exposure to flavourings (expressed as $\mathrm{mg} \mathrm{kg}^{-1}$ body weight day ${ }^{-1}$ ) in a sample of 121 adults from The Netherlands (food consumption combined with refined concentration data $\left.^{\dagger}\right)$

\begin{tabular}{|c|c|c|c|c|c|c|c|c|c|c|c|c|c|}
\hline \multirow[b]{4}{*}{ Flavourings } & \multirow[b]{4}{*}{$\begin{array}{l}\text { Safety } \\
\text { limits }^{\ddagger}\end{array}$} & \multicolumn{12}{|c|}{ Dietary exposure assessment (Steps 2 and 3) } \\
\hline & & \multirow{2}{*}{\multicolumn{3}{|c|}{ 2: Food group level }} & \multicolumn{9}{|c|}{ Food item level } \\
\hline & & & & & \multicolumn{3}{|c|}{$\begin{array}{l}\text { 3a: without improvement of } \\
\text { descriptors in the EPIC-Soft }\end{array}$} & \multicolumn{3}{|c|}{$\begin{array}{l}\text { 3b: with improvements of } \\
\text { descriptors in the EPIC-Soft }\end{array}$} & \multicolumn{3}{|c|}{$\begin{array}{l}\text { 3c: all foods from step } 3 a \text { anc } \\
3 b \text { plus the foods where } \\
\text { 'unknown' descriptor in the } \\
\text { facet flavour was reported }\end{array}$} \\
\hline & & Mean & Median & P95 ${ }^{\text {th }}$ & Mean & Median & $\mathrm{P} 95^{\text {th }}$ & Mean & Median & $\mathrm{P} 95^{\text {th }}$ & Mean & Median & $\mathrm{P} 95^{\text {th }}$ \\
\hline Raspberry Ketone & 0.03 & 0.08 & 0.07 & 0.18 & $<0.01$ & 0 & $<0.01$ & $<0.01$ & $<0.01$ & 0.04 & 0.01 & $<0.01$ & 0.05 \\
\hline Glycyrrhizinic acid & 0.16 & 0.46 & 0.34 & 1.37 & 0.11 & $<0.01$ & 0.46 & - & - & - & 0.13 & $<0.01$ & 0.52 \\
\hline Coumarin & 0.10 & 0.07 & 0.06 & 0.12 & $<0.01$ & $<0.01$ & 0.02 & - & - & - & $<0.01$ & $<0.01$ & 0.02 \\
\hline Caffeine & 6.7 & 18.6 & 17.0 & 43.5 & 6.81 & 5.47 & 16.8 & - & - & - & 6.82 & 5.47 & 16.8 \\
\hline
\end{tabular}

"Sample population is part of the European Food Consumption Validation (EFCOVAL) project

${ }^{\dagger}$ Concentration values from normal use levels and analytical determinations

₹ Raspberry ketone: Threshold of Toxicological Concern in relation to structural class I (Cramer, et al. 1978); Glycyrrhizinic acid: Provisional LOAEL, (SCF 2003); Coumarin: Tolerable Daily Intake (EFSA 2004b); Caffeine: Tolerable daily intake (Fabech, et al. 2002). 

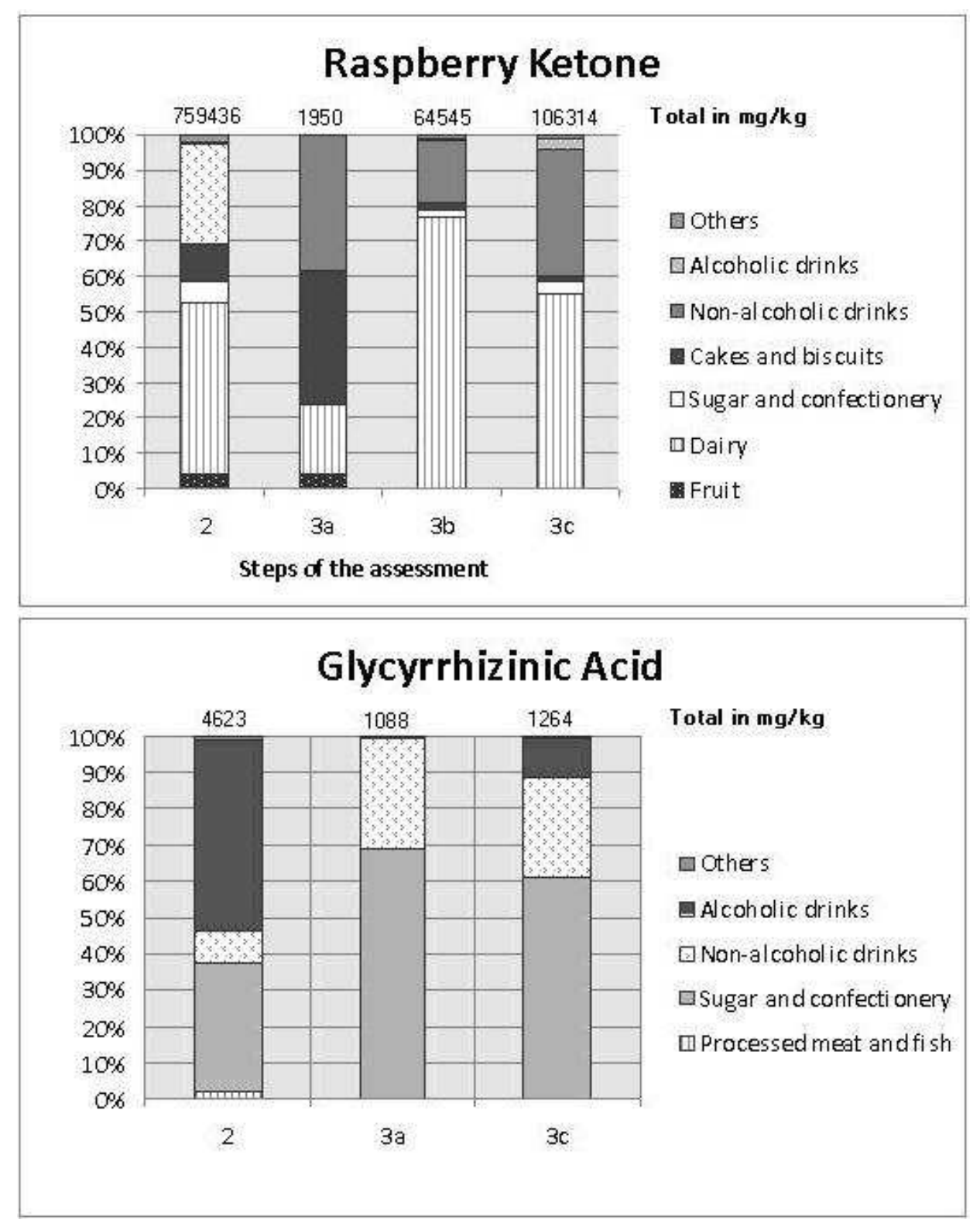

Figure 1 - Dietary exposure to raspberry ketone and glycyrrhizinic acid and their food group sources in each step (2,3a, $3 b$ and $3 c)$ of the assessment.

2 - Food group level: All foods belonging to a flavourable food group are included in the model. $3 a$ - Food item without modifications in EPIC-Soft $3 b$ - Food item with modifications in EPIC-Soft $3 c-$ Steps $3 a$ and $3 b$ plus foods which were reported as non-specified flavour. $141 \times 179 \mathrm{~mm}(96 \times 96 \mathrm{DPI})$ 
Appendix 1 - Flavourable food groups considered in the dietary exposure assessment of step 2

\begin{tabular}{|c|c|c|c|}
\hline Raspberry Ketone & Glycyrrhizinic Acid & Coumarin & Caffeine \\
\hline $\begin{array}{l}\text { Alcoholic beverages (liqueurs, } \\
\text { brandies, gin subgroups) }\end{array}$ & $\begin{array}{l}\text { Alcoholic beverages (spirit, aniseed } \\
\text { drinks and liqueur subgroups) }\end{array}$ & $\begin{array}{l}\text { Alcoholic beverages (wine, beer } \\
\text { subgroups) }\end{array}$ & $\begin{array}{l}\text { Alcoholic beverages (liqueur } \\
\text { subgroup) }\end{array}$ \\
\hline Biscuits & Dressing sauces & Biscuits & Breakfast cereals \\
\hline Breakfast cereals & Fish products & Breads & Cakes and biscuits \\
\hline Cakes & Liquorice confectionery (non- & Breakfast cereals & Dairy products (milk beverages and \\
\hline Dairy products (yogurt, milk & confectionery chocolate and ice & Cakes & cream desserts subgroups) \\
\hline beverages, cream desserts, & cream subgroups) & Dairy products (desserts subgroup) & Dessert sauces \\
\hline puddings subgroups) & Non-alcoholic beverages (herbal tea & Dessert sauces & Non alcoholic beverages \\
\hline Dressing and dessert sauces & subgroup) & Fruits & (carbonated drinks, coffee, tea \\
\hline Fruits & Processed meats & Non-alcoholic beverages & subgroups) \\
\hline Non-alcoholic beverages & & Root vegetables & Sugar and confectionery (syrup, \\
\hline $\begin{array}{l}\text { Sugar and confectionery (jams, non- } \\
\text { chocolate, ice cream, sorbet, water } \\
\text { ice subgroups) }\end{array}$ & & Sugar confectionary & chocolate bar, ice cream subgroups) \\
\hline
\end{tabular}


Appendix 2 - Refined concentrations ${ }^{*}$ used in the dietary exposure assessment of steps 2 (food group level) and 3 (food item level)

\begin{tabular}{|c|c|c|c|c|c|c|c|}
\hline \multicolumn{2}{|c|}{ Raspberry Ketone } & \multicolumn{2}{|c|}{ Glycyrrhizinic Acid } & \multicolumn{2}{|l|}{ Coumarin $^{\dagger}$} & \multicolumn{2}{|l|}{ Caffeine } \\
\hline Foods & $\mathrm{mg} \mathrm{kg}^{-1}$ & Foods & $\mathrm{mg} \mathrm{kg}^{-1}$ & Foods & $\mathrm{mg} \mathrm{kg}^{-1}$ & Foods & $\mathrm{mg} \mathrm{kg}^{-1}$ \\
\hline & 1 & & & & & & \\
\hline Baked goods & 13.1 & Alcoholic beverages & 135 & Baked goods & 16.6 & Baked goods & 0.06 \\
\hline Chocolate $(n=2)$ & $9.3 \pm 9.1$ & Liquorice confectionery & 1500 & Bilberry & 0.005 & Brewed Coffee & 680 \\
\hline Ice cream & 2.6 & Non-alcoholic beverages & 50 & Breakfast cereal & 7.5 & Cocoa powder & 340 \\
\hline Jam & 0.3 & Soy sauce $(n=5)$ & $37 \pm 19.4$ & Celery & 16.6 & Chocolate milk & 60 \\
\hline Non-alcoholic beverages & 2.8 & & & Cinnamon powder & 3000 & Chocolate syrup & 106 \\
\hline Raspberry ( $n=39$ ) & $1.3 \pm 1.2$ & & & Dairy products & 1.1 & Cola drinks & 125 \\
\hline Sauce & 0.9 & & & Frozen dairy & 1.1 & Dark chocolate & 700 \\
\hline Yogurt & 20.2 & & & Jam & 2.9 & Espresso & 2473 \\
\hline & & & & Non-alcoholic beverages & 0.06 & Energy drinks & 240 \\
\hline & & & & Pudding & 3.8 & Puddings & 0.3 \\
\hline & & & & & & Frozen dairy & 0.3 \\
\hline & & & & & & Liquor & 170 \\
\hline & & & & & & Milk chocolate & 220 \\
\hline & & & & & & Tea & 205 \\
\hline & & & & & & White chocolate & 14 \\
\hline
\end{tabular}

* Number of samples used $=1$ unless otherwise specified; in that case mean $+/$ - SD are reported. See methods section.
${ }^{\dagger}$ Based on percentage of coumarin in cinnamon products (cassia cinnamon: $0.3 \%$ (BfR 2006)) and in the use levels of cinnamon reported by FEMA (Flavour and Extract Manufacturers' Association) at Fenaroli's Handbook of flavour ingredients (Burdock 2005), except for bilberry and celery, which were collected from the literature. 